\title{
Psicologia social do trabalho sujo: revendo conceitos e pensando em possibilidades teóricas para a agenda da psicologia nos contextos de trabalho
}

\author{
Social Psychology of the Dirty Work: Reconsidering \\ Concepts and Suggesting Theoretical Possibilities to \\ the Psychology's Agenda in Work Contexts
}

Recibido: marzo 4 de 2013 | Revisado: mayo 30 de 2013 | Aceptado: septiembre 1 de 2013

\author{
Pedro F. Bendassolli* \\ JoRgE T. DA Rocha FALCÃO \\ Universidade Federal do Rio Grande do Norte, \\ Brasil
}

Doi: 10.11144/Javeriana.UPSY12-4.psts

Para citar este artículo: Bendassolli, P. F., \& da Rocha Falcão, J. T. (2013). Psicologia social do trabalho sujo: revendo conceitos e pensando em possibilidades teóricas para a agenda da psicologia nos contextos de trabalho. Universitas Psychologica, 12(4), 1153-1166. Doi: 10.11144/Javeriana.UPSY12-4. psts

Correspondência concernente a este artigo deve ser encaminhada para um dos autores, no endereço: Universidade Federal do Rio Grande do Norte, Departamento de Psicologia, Av. Senador Salgado Filho, s./n., Cidade Universitária, Natal/RN, Brasil. CEP 59072-970.E-mails: pbendassolli@gmail.com; falcao.jorge@gmail.com
RES U M O

O artigo propõe uma análise do conceito de trabalho sujo. Argumenta que esse tipo de trabalho pode contribuir para a ampliação de temas investigados pela psicologia social do trabalho. Em termos metodológicos, primeiramente recupera e atualiza o sentido de trabalho sujo tal como proposto originalmente por autores da Escola de Chicago. Em seguida, desenvolve uma reconceptualização do trabalho sujo a partir da incorporação de referenciais oriundos das clínicas do trabalho. Defende que o trabalho sujo não deve ser confundido com outras formas de trabalho estudados pela psicologia social. Argumenta que o conceito deve ser restrito às atividades em que não se identifica um coletivo de trabalho constituído. Por fim, discute desafios teóricos ao estudo do trabalho sujo, bem como oferece sugestões para pesquisadores interessados nesta temática.

Palavras-chave autores

Trabalho sujo, trabalho penoso, estigma social, clínicas do trabalho.

Palavras-chave descriptores

Psicologia social, pesquisa qualitativa, trabalho.

\section{A B S T R A C T}

This paper aims to propose an analysis of dirty work. It is argued that this kind of work may contribute to an enlargement of the Social Psychology of Work agenda. In methodological terms, firstly the paper recasts and refreshes the meaning of dirty work such as originally proposed by Chicago School members. Next, a reconceptualization of dirty work is carried out, based on the frame of reference developed in the work clinics field. The paper argues that dirty work should not be confused with other kinds of work studied by Social Psychology. It holds that dirty work refers only to those activities in which one can't identify an instituted sense of collective work. Finally, the paper discusses theoretical challenges in studying dirty work, making suggestions for researchers interested in this subject.

Key words authors

Dirty Work, Hard Work, Social Stigma, Work Clinics.

Key words plus

Social Psychology, Qualitative Research, Work. 


\section{Introdução}

Em 2005, uma série lançada pelo canal Discovery Channel, Dirty Jobs (trabalhos sujos), chamou a atenção da audiência. Cada um dos episódios, apresentados por Mike Rowe, mostrava trabalhos insalubres e exigentes fisicamente, detalhando as atividades inerentes à sua realização. $O$ telespectador ficava então sabendo como era o trabalho de criadores de porcos, de jacarés e de outros animais estranhos e perigosos; de plantadores de cogumelos; coveiros; de pesquisadores de cobras; de trabalhadores do sexo; de trabalhadores que manipulam lixo hospitalar; dentre uma infinidade de outros trabalhos pouco conhecidos, negligenciados pelo grande público, e, sobretudo, trabalhos que poucos desejariam fazer.

O estudo do trabalho sujo não é recente. Ele ganhou visibilidade com as pesquisas realizadas por investigadores da Escola de Chicago, nas primeiras décadas do século vinte, num esforço mais amplo de aproximar a ciência dos problemas sociais. Foi nesse contexto que Hughes (1958) cunhou o termo trabalho sujo (dirty work) para se referir àquelas situações e atividades de pouco prestígio e visibilidade social, em geral estigmatizadas, inobstante serem importantes para a reprodução social. Estudar o trabalho sujo, na perspectiva em que ele foi originalmente concebido, implica na compreensão de quais dimensões, psicossociais, econômicas, morais, estão envolvidas na existência e na realização desses tipos de atividades, e na discussão da própria dinâmica social e dos processos de constituição dos sujeitos.

Desde sua proposição como objeto de pesquisa, o trabalho sujo passou a ocupar, ao longo do século vinte, a pauta de pesquisadores nos mais variados campos das ciências humanas e sociais, em especial na sociologia. No campo da psicologia social do trabalho brasileira, foco deste artigo, a utilização do conceito de trabalho sujo é praticamente inexistente, embora haja exceções (eg.: Arantes, 2011; Barros, 2010; Barros \& Lhuilier, 2013; Barros \& Santos, 2013; Da Rocha Falcão, 2012). Contudo, desde, pelo menos, o final da década de 1970, diversas atividades que compõem o domínio do trabalho sujo passaram a ser investigadas por psicólogos sociais do trabalho, ainda que não reconhecidas como tais.

As razões do interesse pela investigação dessas atividades são de ordem epistemológica e ético-política. A psicologia social do trabalho, em suas várias acepções ao longo das últimas décadas (por exemplo: libertadora, transformadora, e, mais recentemente, crítica), vem se desviando, conscientemente, da matriz neopositivista que esteve, e ainda está, presente no campo das ciências do trabalho. No caso da psicologia, a matriz neopositivista desdobra-se no referencial cognitivo-comportamental, que segue como base importante para a psicologia das organizações na atualidade (Bendassolli, 2011; Bendassolli, Borges-Andrade \& Malvezzi, 2010). Esse referencial coloca ênfase na preditibilidade e no controle do comportamento em contextos de trabalho, agindo como uma tecnologia social a serviço do incremento da performance. A consequência ético-política dessa postura epistemológica é a criação e priorização de pautas de pesquisa instrumentais, nas quais o trabalho é entendido, predominantemente, como atividade geradora de valor econômico.

O distanciamento da psicologia social (crítica) do trabalho da matriz neopositivista implica, de um lado, no desenvolvimento de uma pluralidade de referenciais teóricos para compreender os contextos de trabalho e, de outro, num posicionamento em que o trabalho não é entendido apenas como uma atividade produtora de valor econômico, nem se restringe ao regime formal de emprego ou às organizações, com suas demandas por performance e ajustes comportamentais. Implica, também, em uma postura ético-política que transforma os contextos de trabalho de campo de aplicação de saberes técnicos especializados (e neutros) para campo de problematização e questionamento das tensões inerentes à relação capital-trabalho (Sato, 2010; Spink, 1996). Esse posicionamento está na origem da ampliação e diversificação da agenda de pesquisas em psicologia social do trabalho. Como dito, essa ampliação incorpora atividades pertencentes aos domínios do trabalho sujo, embora isso não seja explicitado ou reconhecido pelos pesquisadores da 
área. $\bigcirc$ propósito deste artigo é contribuir para essa explicitação ou reconhecimento.

Em particular, defendemos a tese central de que o conceito de trabalho sujo é um tema estratégico para a psicologia social crítica do trabalho. Esta tese será sustentada em função de alguns argumentos. Primeiro, mostraremos que o trabalho sujo pode servir como um conceito integrador, colocando as atividades hoje investigadas de modo isolado numa perspectiva de fenômeno integrado. Por exemplo, o que haveria em comum nas atividades realizadas por prostitutas, catadores de papel, egressos do sistema prisional, ambulantes, deficientes físicos, trabalhadores em canaviais, coveiros, e tantas outras atividades incluídas na agenda ampliada da psicologia social do trabalho brasileira? A penosidade, a vulnerabilidade, a exclusão, a invisibilidade, as estratégias de resistência e enfrentamento? Por meio de uma reconceitualização do trabalho sujo, algumas respostas serão oferecidas a estas questões.

Segundo, mostraremos que o conceito de trabalho sujo implica na necessidade de explicitar o que entendemos por trabalho. Nesse ponto, propomos uma aproximação conceitual entre as clínicas do trabalho (Bendassolli \& Soboll, 2011; Lhuilier, 2006) e a psicologia social crítica do trabalho. A partir dessa aproximação, mostraremos que em toda atividade de trabalho existe uma dimensão de confronto com o real que não pode ser apagada, nem pelos ideais (higienistas) embutidos em conceitos como os de "melhores práticas" organizacionais, nem pela perspectiva da "revolução social" e diluição das tensões capital-trabalho. É inerente, na atividade de trabalho, um elemento ontológico de relação do sujeito com o real, com algo do mundo ou de si mesmo que impõe resistências e que necessitam ser superadas.

O terceiro argumento a ser desenvolvido é de que o trabalho sujo pode se sobrepor, embora não deva ser confundido, com diversas outras categorias ou conceitos utilizados pela psicologia social (crítica) do trabalho. Por exemplo, os conceitos de trabalho informal, precário, marginal, invisível, placardizado, vazio. Esses conceitos, embora possam ser necessários, não são suficientes para abarcar a totalidade do conceito de trabalho sujo.
Assim, mais uma vez nos baseamos na aproximação às clínicas do trabalho para argumentar que existem dimensões psicossociais chaves que definem o trabalho sujo. Em sua essência, defendemos que o trabalho sujo deve ser reservado àquelas atividades privadas do entorno de um coletivo de trabalho. As implicações da ausência desse coletivo serão exploradas em detalhes.

O quarto e último argumento é uma consequência dos argumentos anteriores, e consiste em questionar a ideia de que o trabalho sujo seja, necessariamente, fator de impedimento ao desenvolvimento psicológico do sujeito, ou então ao que entendemos, do ponto de vista ético, como uma sociedade justa. Esse argumento deriva do conceito de trabalho sujo proposto neste artigo. Assim, elencamos alguns desafios teóricos que consideramos fundamentais à investigação do trabalho sujo pela psicologia social. Ao fazê-lo, esperamos atingir um último objetivo com este texto: subsidiar, conceitualmente, a ampliação de pauta da psicologia social crítica do trabalho.

Do ponto de vista metodológico, este é um artigo conceitual. Estruturalmente, na primeira seção, resgatamos o sentido original de trabalho sujo, tal como formulado na tradição da Escola de Chicago. Ao mesmo tempo, ainda nesta seção, realizamos uma revisão da literatura para apresentar ao leitor o que vem sendo discutido sobre esse assunto na literatura internacional. $\mathrm{O}$ critério básico para a escolha dos textos desta seção é o foco do artigo: foram escolhidos aqueles em que o objetivo era a discussão do trabalho sujo, ou então que o usassem como categoria de análise. Não foram incluídos textos provenientes da literatura brasileira, pois estes não foram encontrados. Contudo, exceções foram identificadas, e elas são sinalizadas ao longo de todo este artigo.

$\mathrm{Na}$ segunda e terceira seções nos dedicamos a uma reconceptualização do trabalho sujo. Isso será feito por meio da utilização de elementos conceituais propostos nas clínicas do trabalho, em particular na clínica da atividade (Bendassolli \& Sobol, 2011; Clot, 2008). Argumentaremos por que o trabalho sujo deveria ser reservado a atividades "frias", nas quais não se identifica a mediação de 
um coletivo de trabalho. Em termos metodológicos, como dito, estas duas seções propõem uma aproximação entre os campos da clínica do trabalho e da psicologia social crítica.

Por fim, na quarta seção nos dedicamos à discussão de alguns desafios conceituais coerentes com a reconceitualização de trabalho sujo apresentada nas seções anteriores. Em particular, são discutidos três desafios - a relação entre trabalho sujo e saúde, desenvolvimento psicológico e qualidade (trabalho bem feito). Citamos duas razões para a discussão desses desafios em específico. Primeira, pois eles referem-se a aspectos centrais para a clínica da atividade, em sua proposta de repensar o sentido de trabalho/atividade no interior da psicologia do trabalho, algo que consideramos promissor se incorporado pela psicologia social do trabalho. Segunda, pois são três desafios, cujo enfrentamento depende da valorização, conceitual, metodológica e prática, dos coletivos de trabalho. Tais coletivos são operadores a partir dos quais as dimensões "nocivas" do trabalho sujo podem, guardadas as devidas proporções, ser transformadas. Esses desafios partem do princípio, defendido neste artigo, de que o trabalho sujo consiste de um fenômeno que, ao mesmo tempo, pode ser fator de sofrimento, exclusão e marginalização, e também, como qualquer atividade de trabalho, sob certas circunstâncias, estar aliado à saúde, ao desenvolvimento psicológico e à realização de um trabalho bem feito (qualidade).

\section{Sociologia do Trabalho Sujo}

O termo dirty work, ou trabalho sujo, foi primeiramente proposto por Hughes (1951), para quem tal trabalho se referia a tarefas e ocupações percebidas como degradantes ou que provocavam alguma forma de nojo. $\mathrm{O}$ adjetivo dirty, na designação de Hughes, remete à ideia de estigma ou de mancha (taint), podendo ocorrer no plano físico, social e moral. Dessa forma, o sujo pode aplicar-se a algo fisicamente repulsivo; a alguma coisa que age como um símbolo de degradação, a alguma coisa que retira a dignidade de uma pessoa; ou, em termos morais, a algo indesejado no plano dos ideais, na medida em que é contrário às concepções "heróicas" da própria sociedade (Hughes, 1951, p. 319). Um pouco mais tarde, Hughes (1958) simplesmente definiu dirty work como tarefas que são "física, social e moralmente manchadas [tainted]" (p. 122).

Expandindo a partir desses trabalhos seminais de Hughes (1951, 1958), Ashforth e Kreiner (1999) indicam que a dimensão física do trabalho sujo pode ser observada em empregos ou ocupações associadas com lixo, morte, fluidos corporais, esgoto, ou condições perigosas. Por sua vez, o estigma social vinculado a esse mesmo trabalho pode ser identificado na exigência para que os "trabalhadores sujos" adotem uma postura de subserviência em relação aos outros, ou então para que mantenham contato com pessoas estigmatizadas (por exemplo, criminosos ou pacientes com doenças altamente contagiosas). Já o estigma moral envolvido na realização de trabalhos sujos ocorre quando uma ocupação é geralmente retratada como uma atividade moralmente reprovável. Ashforth e Kreiner observam que uma mesma pessoa pode vivenciar todas essas formas de estigma ao mesmo tempo - como, por exemplo, no caso da prostituição. Publicações recentes têm investigado diversas ocupações e suas respectivas exposições a uma ou outra destas três principais formas de estigmatização (e.g.: Drew, Mille, \& Gassaway, 2007; Simpson, Slutskaya, Lewis, \& Höpfl, 2012).

$\mathrm{Na}$ avaliação de Hughes (1962), a sociedade delega o trabalho sujo a grupos que atuam como agentes dessa mesma sociedade, mas que, em contrapartida, são por ela estigmatizados. Em outras palavras, a mesma sociedade que cria a demanda e necessidade por trabalhos sujos priva aqueles que os realizam de um status social observado em outras ocupações ou esferas da vida social. Ashforth e Kreiner (1999) observam que o estigma associado ao trabalho sujo, paradoxalmente, impulsiona o desenvolvimento de culturas de trabalho fortes, e fomenta a utilização de mecanismos de defesa que transformam o significado de sujo e moderam o impacto das percepções sociais de sujeira e seus derivados simbólicos. Assim, não haveria uma ligação direta entre a realização de trabalhos sujos e a degradação das representações de si; pelo contrário, 
os que sofrem estigma social pelo fato de realizarem trabalhos sujos constroem identidades sociais sob o amparo de comunidades ocupacionais ou de coletivos de trabalho. Voltaremos a este ponto mais adiante neste artigo, inclusive porque, na nossa avaliação, esta representa uma importante frente de atuação da psicologia do trabalho nos domínios do trabalho sujo.

Outros autores têm discutido o trabalho sujo no contexto de representações, socialmente construídas, sobre o que se entende, num determinado registro sócio-histórico, por bom trabalho e mal trabalho, sendo o trabalho sujo mais próximo deste último. O bom trabalho, sugere Bolton (2007), oferece a possibilidade, para quem o realiza, de encontrar aspectos intrinsecamente motivadores, além de permitir reconhecimento e ascensão social, desenvolvimento de carreira e demais contrapartidas econômicas (salário, plano de saúde, previdência, etc.). Ainda segundo Bolton, o bom trabalho implica, em geral, distanciamento das fontes de sujeita. Já o mal trabalho está associado a ambientes laborais com elevado risco, a ocupações de baixa remuneração, à dificuldade de permitir a quem o realiza desenvolver-se em termos de carreira. Porém, como destaca Drew et al. (2007), todo trabalho pode conter alguma parcela de sujeira. Isso quer dizer que o trabalho sujo não deveria ser pensado apenas como ocorrendo em setores informais, precários, ou então em ocupações que lidam com condições física e socialmente degradantes.

Neste sentido mais amplo, sujeira refere-se a algo desprazeroso, àqueles aspectos do trabalho que exigem do trabalhador um engajamento que não vem de si próprio (intrinsecamente), remetendo à ideia de que há, em qualquer trabalho/ocupação, elementos de uma atividade forçada (Schwartz, 1994). Em nossa avaliação, em todo trabalho há necessidade de o sujeito confrontar-se com o real da atividade, com aquilo que é imposto por esta ao sujeito e com o que este deve lidar para realizar sua tarefa. Desenvolvemos melhor esta ideia a seguir, antes de propormos uma definição alternativa para o conceito de trabalho sujo.

\section{Trabalho Sujo e o Real da Atividade}

O conceito de trabalho sujo pode ser alvo de interpretações equivocadas, levando a concepções equivocadas sobre o próprio sentido de trabalho e trabalhar. Como sugerimos na seção anterior, ao definirmos um trabalho como sujo, podemos partir de um pressuposto de que, do ponto de vista moral, este é um mal trabalho e que, como tal, deve ser erradicado, já que produz situações de risco, vulnerabilidade e invisibilidade das pessoas. Porém, esse tipo de pressuposto traz em si um risco, que é o de desconsiderar a dimensão real (Lhuilier, 2006) que permeia qualquer tipo de trabalho/atividade.

Por exemplo, considere-se o trabalho de um agente funerário encarregado de preparar cadáveres para exposição pública (velório) e sepultamento. Considerado um trabalho sujo (Hughes, 1951, 1958; Lhuilier, 2006), sua realização é parte intrínseca e socialmente reconhecida ${ }^{1}$ do funcionamento das sociedades ocidentais, no sentido de que é uma necessidade imposta pelo próprio cotidiano dessas sociedades. Na história do capitalismo, vários trabalhos sujos foram eliminados graças a inovações tecnológicas, as quais incorporam a realização de atividades que antes precisavam ser feitas por pessoas em condições absolutamente degradantes (física e moralmente). O trabalho do agente funerário é um trabalho que, por mais que haja desenvolvimentos tecnológicos, continuará a ter de ser feito e continuará a confrontar quem o realiza com os limites, as resistências por assim dizer, do real da atividade.

Portanto, a dimensão moral e/ou valorativa implicada no trabalho sujo não necessariamente coincide com sua dimensão psicológica, no sentido de que haverá um sujeito implicado na sua realização, mergulhado no contexto de um coletivo de trabalho. Essa dimensão psicológica nos permite questionar: não haveria desenvolvimento

1 Uma evidência de tal reconhecimento no Brasil é o fato de que esta atividade profissional consta da Classificação Brasileira de Ocupações (CBO), sob a rubrica "Agente funerário / Tanatopraxista", código 5165-05 (Ministério do Trabalho, 2010). Observe-se que nem todo "trabalho sujo" tem tal reconhecimento, como é o caso da gama de ocupações da informalidade. 
psicológico daqueles que realizam trabalhos sujos, notadamente nos casos em que tais modalidades de atividade profissional começam a se inscrever em coletivos de trabalho articulados, como é o caso dos agentes de limpeza urbana (outrora lixeiros) em grandes capitais brasileiras, que se organizam em cooperativas (Leite, Oliveira, Pinto de Paula, 2012).

Ao mesmo tempo, certos trabalhos sujos só existem como tais por conta de exigências objetivas das condições de produção no atual ciclo do desenvolvimento capitalista. Pense-se no caso de um operador de elevadores em prédios urbanos, o ascensorista (ocupação profissional catalogada na Classificação Brasileira de Ocupações sob código 5141-05 (Ministério do Trabalho, 2010). Em se admitindo tratar-se de um trabalho sujo, sua realização tornou-se supérflua considerando-se a própria inovação tecnológica na operação de elevadores. Nesse contexto especifico, o conceito de trabalho sujo alude à dimensão do trabalho esvaziado. Para autores como Lhuilier (2002), o trabalho esvaziado é denominado travail placardisé, e se refere a modalidade específica de ocupação profissional desqualificada, e/ou em processo de esvaziamento, destinado ao depósito inerte em algum placard [estante] do desuso, da desvalorização (em vários planos) e no limite, da extinção. Tal acepção do trabalho sujo, diga-se de passagem, amplia esse conceito na direção da violência organizacional do tipo assédio moral em contexto de trabalho (bullying, na literatura anglófona, harcèlement, na literatura francófona). Para autores como Grima e Muller (2006), o processo complexo de esvaziamento de atividades ocupacionais e a manutenção/encaminhamento de trabalhadores para tais atividades deveriam ser vistos como uma modalidade parcial de violência do tipo assédio moral.

A dimensão do real da atividade impõe-se a qualquer um encarregado de lidar com a materialidade por meio do trabalho. Contudo, um aspecto fundamental desta relação com o real diz respeito à diversidade de recursos de mediação de que dispõe o indivíduo, pois tal confronto não ocorre num vácuo, nem cultural nem psicossocial. O problema com o trabalho sujo, como veremos, é a possibilidade de ele levar o sujeito ao esquecimento, à perda de contato com contextos de mediação e suporte sociocultural. Privado do contato com os coletivos de trabalho, a atividade suja contamina quem a realiza, esfriando a relação do sujeito com o real. Assim, mais grave do que a sujeira do trabalho sujo é o risco de solidão a que tal modalidade de trabalho pode conduzir, relegando o sujeito-trabalhador à tarefa de lidar com o real em contexto de escassez de referências de um coletivo de trabalho e/ou gênero profissional. Na próxima seção, propomos uma redefinição do conceito de trabalho sujo a partir dessa característica essencial da relação do homem com o trabalho: sua natureza social, semiótica: mediadora e mediatizante face o real.

\section{Dimensões Psicossociais do Trabalho Sujo}

Antes, porém, de nos voltarmos para a análise da mediação do coletivo no contexto do trabalho sujo, propomos, nesta seção, uma síntese das principais dimensões psicossociais para se definir e compreender o trabalho sujo, coerente com o que discutimos nas seções anteriores em relação à literatura sociológica e com o que vem sendo desenvolvido por autores filiados às clínicas do trabalho (Bendassolli \& Soboll, 2010; Lhuilier, 2006). Tratam-se de dimensões básicas, não necessariamente excludentes, destinadas a abarcar o conceito de trabalho sujo numa discussão de psicologia (social) do trabalho. Ao todo, serão arroladas cinco dimensões.

Há, inicialmente, a dimensão referente ao reconhecimento desta modalidade de trabalho enquanto tal: para muitos economistas que analisam aspectos macroeconômicos e referentes ao comportamento, nas economias contemporâneas, do perfil de emprego-desemprego, várias modalidades de trabalho sujo não passariam de desemprego disfarçado (Mansur, 2012), não-emprego, subemprego, ou, de forma menos pejorativa, trabalho informal. É o caso, por exemplo, dos trabalhadores que exercem atividade de comércio não-regular -em termos de tributação e submissão a outras formas de regramento jurídico-econômico, como classificações profissionais nacionais, e que, frequentemente, se referem a tais atividades como quebra-galho, bico, viração. 
Uma segunda dimensão diz respeito à esfera do prazer-desprazer, frustração, humilhação e raiva como emoções frias (Spinoza, 1977/1965; Viana, Maia Filho, Oliveira, \& Pereira Neto, 2012; Santiago-Delefosse, 2004) caracterizadoras da vivência subjetiva de quem exerce um trabalho sujo. Partindo-se do pressuposto que o sistema afetivo-emocional deve ser visto como um operador psicológico complexo que não age necessariamente sobre o objeto psicológico, e sim sobre o sujeito que se relaciona com este objeto, a emoção se configura como um ato instrumental expressivo (Santiago-Delefosse, 2004) que manifesta uma atividade relativa a si mesmo, aos outros e ao contexto mais amplo. Trata-se, em outras palavras, de mediador inescapável entre a vivência subjetiva do indivíduo e o mundo que o cerca. Tal atividade mediadora pode ocorrer sobre a base do que Spinoza chamou de emoções frias; tais emoções dificultam o desenvolvimento psicológico notadamente por seu potencial no sentido de induzir o sujeito ao isolamento, à solidão pouco produtivos, conforme explica Sévérac, ao referir-se ao afeto de consternação, como tristeza paralisada pela admiração: "A admiração de um mal mantém o homem de tal maneira suspenso na pura contemplação desse mal que não é capaz de pensar em outras coisas, pelas quais poderia evitar esse mal" (Sévérac, 2009, p. 30).

Uma ilustração do que se alude aqui diz respeito às vivências em contexto de trabalho referidas pelos rodeiros $^{2}$ da cidade de Natal (RN-Brasil), para os quais "o que a gente mais tem aqui [no exercício de sua atividade de trabalho] é raiva"; "eles [motoristas] tratam a gente como cachorro, (...) uma vida sem futuro" (Taques \& Leal, 2012). Voltaremos mais adiante a aludir acerca desse caso específico dos rodeiros, tendo em vista o objetivo central desse artigo, voltado para a reconceitualização do domínio do trabalho sujo.

2 "Rodeiro"é o termo adotado na cidade de Natal (RN) para a atividade daqueles que se oferecem para lavar rapidamente os pára-brisas de automóveis durante o curto tempo em que param nos semáforos de trânsito, com o auxílio de um rodo, instrumento auxiliar para tal lavagem, em troca de pequenas quantias de dinheiro.
Uma terceira dimensão diz respeito a aspectos relacionados à esfera da moralidade-legalidade da atividade de trabalho em questão, ou seja, o interfaceamento e imbricamento da atividade de trabalho com delitos tipificados juridicamente como, por exemplo, tráfico de drogas, prostituição e proxenetismo, exploração do trabalho infantil, aluguel de identificação de pessoa física a terceiros, entre outros.

Uma quarta dimensão do trabalho sujo diz respeito à baixa desejabilidade social ou representação social depreciativa da atividade em questão, seja por razões de riscos à saúde inerentes à atividade em questão (como no caso dos coveiros, mantenedores de sistemas de esgotamento e armazenamento de dejetos sanitários, lixeiros e catadores de lixo), seja no caso de indesejabilidade social intrínseca ao tipo de atividade, apesar da aceitação social da ideia de sua necessidade e inevitabilidade, como é o caso da atividade de carrascos (em sistemas jurídicos que comportam a pena de morte administrada pelo Estado), e mesmo médicos especializados em cuidados paliativos para pacientes terminais.

Finalmente, uma quinta dimensão caracterizadora do trabalho sujo, diversa porém próxima da categoria anterior, diz respeito a circunstâncias especiais nas quais se encontra o indivíduo trabalhador e/ou seu coletivo de trabalho: é o caso do trabalho desempenhado por indivíduos em regime de encarceramento e portadores de doenças crônicas ou condições anátomo-fisiológicas alteradas, como é o caso de portadores de AIDS e trabalhadores colostomizados (Lhuilier, 2005).

Em face das cinco dimensões expostas acima, talvez seja o caso de considerar que a categoria conceitual trabalho sujo abarque uma diversidade tal de casos que estaria a merecer recategorização, a bem da homogeneidade dos casos abarcados. Este conceito recobre um amplo espectro de categorias, conforme demonstrado pela análise acima, o que traz um risco de esvaziamento teórico (theoretical emptiness) aludido por Koppe (2012). Para este autor, um determinado conceito teórico pode incorrer em esvaziamento teórico quando é usado em tantos contextos e para recobrir uma tal diversidade de categorias de fenômenos que passa 
a não ter mais valor como operador teórico - de tanto tentar significar, não significa mais nada. A análise do espectro de abrangência do trabalho sujo enquanto operador teórico-conceitual permite observar uma justaposição de perspectivas como a informalidade econômica, experiência subjetiva no exercício da atividade de trabalho, caráter delituoso da atividade, indesejabilidade social intrínseca à atividade e indesejabilidade da condição do indivíduo trabalhador, que "contamina” psicologicamente a própria atividade.

No contexto de um esforço de depuração da categoria trabalho sujo, que dimensão teórica seria crucial para uma nova caracterização do trabalho sujo, no âmbito de uma psicologia social do trabalho inspirada nas clínicas do trabalho, mais especificamente na clínica da atividade?

\section{O Trabalho Sujo como Trabalho Solitário e Frio}

Propomos aqui que uma dimensão crucial presente em várias dimensões discutidas acima (mas não em todas) diz respeito à manutenção, desenvolvimento ou tolhimento do poder de agir do indivíduo trabalhador no âmbito de cada atividade de trabalho considerada (Da Rocha Falcão, 2012). O conceito de poder de agir diz respeito à capacidade do sujeito em superar as contradições, os bloqueios, os impedimentos, as resistências impostos pelo real da atividade ou ainda pela organização e divisão (prescritas) do trabalho (Clot, 2002, 2008, 2010).

Em tal contexto de formulação teórica, e no que diz respeito à consideração do poder de agir para a abordagem da atividade de trabalho como agenciadora do desenvolvimento, saúde ou adoecimento do indivíduo trabalhador, tal construto teórico tem forte relação com a inserção do indivíduo trabalhador em determinado coletivo de trabalho. Tal coletivo, em estágio menos elaborado, diz respeito simplesmente ao grupo de co-participantes de determinada atividade (como o mero ajuntamento de rodeiros em um semáforo), e em estágio mais elaborado, diz respeito a um coletivo organizado, historicizado e organizado como gênero profissional, como é o caso dos catadores de lixo das cooperativas de Belo Horizonte, descritos por Leite et al. (2012).

Neste último caso, mais que um mero ajuntamento de indivíduos agregados por contrato social ad hoc para exploração e proteção de "ponto" de exploração da atividade, tem-se a instauração de uma instância transpessoal que oferece ao indivíduo interlocução, referência e, portanto, margem para sua própria iniciativa de inovação pessoal. Tal iniciativa, que permite a emergência e afirmação de um estilo pessoal, frequentemente se associa à sensação de trabalho bem feito, o que por sua vez traz repercussões positivas para o desenvolvimento da representação de si e da própria saúde mental, como veremos na próxima seção (Clot, 2008, 2010; Clot \& Lhuilier, 2010). Nessa ordem de ideias, poderíamos, por exemplo, estabelecer uma comparação entre as atividades de rodeiros e catadores de lixo, pesquisados, respectivamente, nas cidades de Natal e Belo Horizonte. Diferentemente dos rodeiros de Natal, os catadores de lixo cooperativados da cidade de Belo Horizonte, apesar de compartilharem atividades comumente consideradas como sujas, diferem bastante na medida em que os últimos dispõem da inserção num coletivo de trabalho por eles desenvolvido e articulado, coletivo este que suporta um gênero profissional (cuja denominação mudou de "catador" para "empreendedor social do lixo" - Leite et al., 2012) que enquadra e acolhe o indivíduo trabalhador, salvando-o de uma situação de indigência e isolamento sócio-psicológico que, esta sim, pouco ou nada contribuiria para a representação de si como trabalhador e indivíduo, e engendraria emoções frias conducentes ao empobrecimento, adoecimento e exclusão social.

Raciocínio semelhante poderia ser feito em relação à dinâmica psicossocial que acompanha a passagem de detentos da condição de não-inseridos em atividade profissional e inseridos em atividade como a padaria do presídio. Observa-se que tais detentos deixam, sistematicamente, de se auto-denominarem "internos" ou "vagabundos" e passam a se apresentarem como padeiros (Silva, Da Rocha Falcão, Torres, \& Moreira, 2012). Mais do que a simples oferta de uma atividade que lhes auxilie a fazer passar o tempo (fonte de sofrimento 
psicológico intensa em situação de aprisionamento), a inserção na padaria oferece a cada detento a possibilidade de inserção em coletivo de trabalho que lhes resgata da solidão ou do encarceramento psicológico à condição de "vagabundo" (aquele que apenas acompanha o passar do tempo), oferecendo-the o dinamismo dialógico da inclusão no coletivo dos padeiros.

Para Lhuilier (2005), ao refletir sobre o alcance e limites da contribuição teórica do conceito de poder de agir (Clot, 2008), a situação trágica dos trabalhadores em atividades tais como a dos rodeiros, caracterizadas por uma inserção em coletivo de trabalho escassa ou nenhuma, não ensejaria propriamente poder de agir, e sim "poder de suportar", no sentido de meramente aguentar a solidão, frieza e ausência de perspectiva de sua atividade de trabalho. À situação dos apenados agregar-se-ia, portanto, um novo eixo de tensão: o de "suportar ao agir", conceito que nos auxiliaria a formular então as três dimensões cruciais para a caracterização do trabalho sujo: (1) a disponibilidade de um coletivo de trabalho mais ou menos organizado (2) que permita ao indivíduo trabalhador referência suficiente para a construção de sua autorepresentação, (3) dando-lhe, efetivamente, meios para agir (especificar-se, desenvolver-se, fazer bem seu trabalho e obter prazer com isso e disso), e não simplesmente suportar a diacronia dessa atividade em solidão psicossocial patologizante.

Propomos, então, que a categoria do trabalho sujo seja reservada àquelas atividades laborais solitárias, frias e conducentes à patologia da monotonia, monologia e passividade. Com isso, preservaríamos outras categorizações, como trabatho informal, trabalho desqualificado ou trabalho espúrio, precário, etc. para outras atividades com algum grau possível de sobreposição em relação ao domínio do trabalho sujo, mas em última análise diversas deste. $\bigcirc$ trabalho sujo, finalmente, não é apenas aquele que se caracteriza pela informalidade, indesejabilidade e/ou baixo prestígio social, mas aquele que é operado em regime de isolamento social, configurado pela precariedade ou ausência de afiliação a um coletivo de trabalho (Da Rocha Falcão, 2012).

\section{Desafios Teóricos ao Estudo do Trabalho Sujo}

Nesta seção, discutimos três desafios teóricos ao estudo do trabalho sujo: sua relação com a saúde psíquica, com o desenvolvimento psicológico do trabalhador, e com a qualidade do agir implicada nessas atividades. A escolha por esses desafios em particular leva em conta a proposta de reconceptualização do trabalho sujo que acaba de ser oferecida, para a qual foi decisiva a utilização de referenciais das clínicas do trabalho. Em particular na clínica da atividade, os três desafios a seguir compõem um mapa conceitual voltado a uma discussão do sentido do trabalho em psicologia. Nosso propósito, agora, é extrapolar suas implicações para a análise específica do trabalho sujo pela psicologia social do trabalho.

$\mathrm{O}$ primeiro desafio diz respeito à relação entre trabalho sujo e saúde. Na perspectiva da clínica da atividade, saúde está relacionada a uma potência de afirmação do sujeito perante o real da atividade (Clot, 2010; Lhuilier, 2002, 2005). Afirmar-se perante o real implica em o sujeito ser capaz de manejar, no contexto de um coletivo de trabalho, recursos pessoais, interpessoais, impessoais e transpessoais para a transformação do objeto e de si próprio, contribuindo, desta forma, para um destinatário anônimo, o gênero profissional.

Baseando-se em Canguilhem (1984), Clot (1995), observa que a saúde “(...) se vincula à atividade vital de um sujeito, ao que ele consegue ou não mobilizar de sua atividade no universo das atividades do outro e, inversamente, ao que ele consegue ou não introduzir das atividades do outro no seu próprio mundo" (p. 96). A saúde tem a ver com a instituição de normas, com um posicionamento ativo do sujeito perante a realidade. Portanto, o sofrimento, o adoecimento, estão relacionados à impossibilidade de o sujeito superar os impedimentos intrínsecos e extrínsecos à sua atividade.

Pensando no trabalho sujo, o coletivo de trabalho, fator de mediação imprescindível a ressignificar uma situação que, de outro modo, levaria o sujeito ao isolamento, à frieza e ao esquecimento, atua como recurso de transformação de si e de ressignificação das condições físicas, sociais e morais atreladas 
ao trabalho sujo. Quando inscrito num coletivo de trabalho, o sujeito ressignifica o sujo, como vimos no exemplo dos detentos alocados em atividades de trabalho (padaria). O coletivo torna a atividade algo conectado (enacted), vinculado, retirando-a da invisibilidade social em que pode estar imersa.

A relação entre trabalho e saúde apresentada nos parágrafos anteriores pode nos levar a pensar que, mesmo em condições de trabalho sujo, é possível haver saúde. A princípio, e intuitivamente, isto pode sugerir que, a despeito dos estigmas físico, social e moral associados a este tipo de trabalho, sobre os quais comentamos em seções anteriores, é possível haver afirmação do poder de agir entre pessoas imersas num cenário por vezes desolador. Esse pressuposto traz algumas implicações. Primeira, de que há uma relação intrínseca, fundante ou ontológica no vínculo do sujeito com seu trabalho, seja este qual for. Isso significa que há uma função psicológica (Clot, 1995) no trabalho, pois este sempre irá confrontar o sujeito consigo próprio, os outros e um determinado gênero profissional.

Assim, em vez de realizar uma leitura específica (embora pertinente), segundo a qual o trabalho sujo é par avance fator de adoecimento, sofrimento e exclusão social, propomos uma perspectiva mais sutil, uma que considera a relação do sujeito com sua atividade, confrontados com o real. De forma alguma, porém, tal perspectiva sugere a negação das condições físicas, sociais e morais imbricadas no trabalho sujo em regime capitalista, com sua tendência a externalizar trabalhos penosos, invisíveis, sujos, a membros mais vulneráveis da sociedade, como é, em geral, o caso nos contextos de trabalho sujo. Em vez disso, trata-se de recuperar uma dimensão instituinte, afirmatória, de qualquer atividade de trabalho, sempre que a mesma seja mediada por um coletivo de trabalho vivo.

O segundo desafio conceitual que gostaríamos de comentar, e que está intimamente relacionado ao anterior, é a possibilidade de considerar o trabalho sujo como um trabalho capaz de promover o desenvolvimento de quem o realiza. Como vimos anteriormente, Bolton (2007) observa que o trabalho sujo pode aproximar-se de um mal trabalho. Entre outras características deste último, está sua baixa atratividade como ocupação com prestígio social, bem como sua baixa oferta de elementos de motivação intrínseca, como a possibilidade de crescimento e desenvolvimento. Há, neste ponto, um tipo de juízo de valor que elege, implicitamente, apenas certas ocupações como sendo capazes de permitir o desenvolvimento dos sujeitos. Claro que, neste juízo de valor, está em causa a construção social e a determinação econômica de certas classes sociais, tipicamente fornecedoras de mão-de-obra em ocupações com elevado prestígio e capital social.

Nesse sentido, é de se esperar, por exemplo, que a carreira de executivo em grandes empresas atraia muito mais pessoas (das classes médias, notadamente) do que a ocupação de coveiro e tantas outras que figuram no leque de trabalhos sujos, conforme já pontuamos. Filhos de classes médias, em geral, estudam em colégios de classe média que, por sua vez, contribuem (afora o imaginário social correspondente) para que determinadas profissões/ocupações sejam preferidas em detrimento de outras. Mais uma vez, isso mostra que o trabalho sujo, visto de um ângulo sociológico, pertence ao movimento que Castel (1999) denomina de individualismo negativo: privadas do acesso ao núcleo de proteção social (seja ou não no regime tradicional do emprego), muitas pessoas não têm outra opção a não ser ocupar esses trabalhos socialmente pouco valorizados, apesar de importantes para a próxima sobrevivência/manutenção da sociedade. Quer dizer, não se trata propriamente de um movimento de livre escolha, mas de falta de opção para evitar a desfiliação social.

Contudo, e este é nosso argumento principal, não devemos confundir o status (social) das ocupações/atividades sujas com a função psicológica que estas podem, guardadas as condições aqui discutidas (a presença de um coletivo/gênero de trabalho mediador), desempenhar para as pessoas que delas se ocupam, mesmo que, a princípio, em regime de falta de opção. Esse risco de ocultar o real do trabalho (Lhuilier, 2006) apresenta-se quando se criam discursos que desmerecem e esvaziam de valor certas ocupações. Em nossa perspectiva, atividades sujas, na medida em que mediadas pelo coletivo e confrontando o sujeito com o real, seus 
impedimentos e suas convocações a agir, podem permitir desenvolvimento psicológico. Porém, o que se entender por desenvolvimento?

Na perspectiva da clínica do trabalho, o desenvolvimento psicológico é um movimento, sem direção certa (ou sem linearidade a priori determinada), que alterna duas exigências: a de eficiência e a de sentido (Clot, 2008, 2010). A primeira diz respeito à capacidade de o sujeito manejar os meios de seu trabalho, mais especificamente: os recursos que concorrem para o exercício de sua atividade (Clot, 2008). Ser eficiente, nos contextos de trabalho, significa ser capaz de economizar tempo e energia (não em sentido instrumental estrito, mas de eficiência da ação) na realização da atividade. Por sua vez, a exigência de sentido diz respeito à necessidade de o sujeito responder ao porquê da atividade. A eficiência tem a ver, no contexto teórico em questão, com a realização de um trabalho bem-feito (Clot, 2010). Já o sentido tem a ver com a ideia, desenvolvida originalmente por Leontiev (1978), de que toda ação humana, por ser intencional, depende de um componente energético derivado do campo das intenções, dos motivos e das finalidades da ação (teleologia da ação).

Em acréscimo ao que foi dito, o desenvolvimento psicológico implicado na atividade de trabalho aciona o sujeito, suas capacidades e funções cognitivas superiores. Ele permite, mesmo em condições que, a princípio (para quem olha de fora), poderiam ser desprovidas de sentido e eficiência (contextos de trabalho sujo), o desenvolvimento da inventividade, da sagacidade prática do sujeito, e a possibilidade de produção de sentidos e significados.

Veja-se o exemplo oriundo do campo do desenvolvimento de competências e habilidades em contexto extraescolar: trata-se da situação dos pescadores-navegadores do nordeste do Brasil, denominados localmente de jangadeiros (devido ao fato de conduzirem embarcações denominadas jangadas). Ao analisar o rol de habilidades e competências de jangadeiros de Recife (PE-Brasil), Da Rocha Falcão (2008) observa a sofisticação com que tais indivíduos conduzem suas embarcações à vela, compondo vetorialmente o ângulo da vela em relação ao vento, a direção do leme de popa (leme da parte de trás da embarcação) e a direção de correntes martinhas, de forma a obter, como resultante, a direção e velocidade desejadas para a embarcação, e tudo isso na completa ausência de qualquer base conceitual-formal oriunda de conhecimento escolar.

O terceiro desafio conceitual no estudo do trabalho sujo é a consideração do que consistira um trabalho bem feito neste caso. Clot (2008) defende que a discussão sobre o que constitui um trabalho bem feito é condição fundamental para a saúde no trabalho, para que este último cumpra seu papel de operador do desenvolvimento psicológico. A impossibilidade de discutir tal qualidade produz um sentimento de insignificância nos sujeitos, pois há uma ruptura, na atividade, entre as pré-ocupações dos sujeitos (seus planos, desejos, aspirações) e aquilo que são obrigados a realizar, uma atividade prescrita, vazia de significado. A impossibilidade de realizar um trabalho bem feito, ou de discutir/debater acerca dos critérios envolvidos na qualidade do que se faz, impede as pessoas de se reconhecerem no próprio trabalho, tornando-as estranhas para si mesmas e gerando o que o autor denomina de ativismo sem obra, uma atividade vazia.

As questões que se colocam no contexto do trabalho sujo são: como reconhecer um trabalho bem feito? Quem realiza tal reconhecimento? Novamente, a resposta remete aos coletivos de trabalho. São estes coletivos que dispõem ao sujeito os critérios para se determinar a qualidade do que se faz. Porém, a situação de um sujeito realizando um trabalho sujo remete a possíveis focos de conflito e contradição na gramática de critérios de qualidade: por exemplo, como decidir sobre tais critérios quando o trabalho é social e moralmente estigmatizado, como no caso da prostituição? Quais dilemas e contradições vivenciam as pessoas que exercem estes trabalhos? E o que dizer do trabalho do agente penitenciário, cuja missão é vigiar e, no limite, punir? Em registro menos problemático, o que dizer da qualidade do trabalho em atividades vazias, como pode ser o caso do ascensorista de elevador, exemplo que citamos mais cedo neste artigo? 
Todas estas situações colocam em evidência a importância psicológica da atividade bem feita, da ação realizada no ajuste fino com as expectativas do sujeito que tem de realizar tal ou qual atividade. Restringir nossa compreensão da qualidade a uma dimensão organizacional em sentido estrito (qualidade de produtos, qualidade de serviços, em suma, qualidade conforme critérios instrumentais) é menosprezar uma parcela importante da relação do sujeito com sua atividade, aquela relacionada à estilização, à margem de manobra pela qual o sujeito se coloca na atividade, ainda que sua realização seja antagônica a valores sociais dominantes.

\section{Considerações Finais}

O objetivo deste artigo foi defender a tese de que o conceito de trabalho sujo, a partir de uma reconceptualização que se baseou numa aproximação com as clínicas do trabalho, clínica da atividade em particular, pode ser um operador estratégico para a psicologia social crítica do trabalho, potencializando seu esforço de ampliação de uma agenda de investigação que contribua para a problematização e a transformação dos contextos de trabalho. Fechamos o artigo com algumas sugestões adicionais para os interessados no tema.

Em primeiro lugar, além dos desafios teóricos anteriormente aludidos, há também desafios metodológicos no estudo do trabalho sujo. $\mathrm{O}$ esforço da psicologia social do trabalho de distanciar-se do paradigma neopositivista, e dos respectivos referenciais cognitivo-comportamentais, foi acompanhado de uma ampla revisão e recriação das formas de acessar os fenômenos relacionados ao trabalho. Por exemplo, a psicologia social do trabalho não se restringe aos métodos quantitativos de pesquisa, com uso de medidas padronizadas e desenhos correlacionais, quase-experimentais ou causais, típicos da perspectiva neopositivista. Ela recorre a métodos compreensivos, interpretativos, em geral em desenho de pesquisas qualitativos.

Então, a questão é: como pesquisar o trabalho sujo, levando-se em conta a reconceptualização aqui proposta e a preferência por métodos não-experimentais (por exemplo, qualitativos)? Não temos a pretensão de esgotar essa questão, de modo que iremos apenas sinalizar algumas pistas, coerentes com o desenvolvimento do artigo. Assim, considerando a relação entre trabalho sujo e o real da atividade, proposta na segunda seção, uma consequência metodológica é a necessidade de incorporar métodos que extrapolem o registro falado, em sentido estrito (por exemplo, entrevistas). Será preciso incorporar métodos que enfatizem a dimensão concreta, material, da atividade realizada, e isso num duplo sentido: no do pesquisador, que deverá intensificar o uso de observação e colocar-se, efetivamente, como um co-analista do trabalho do outro, como no do próprio participante da pesquisa, que deverá ser chamado a refletir sobre sua atividade in loco, no momento de sua realização (em vez de recorrer à rememoração sobre a atividade já realizada).

Neste último sentido, uma técnica heuristicamente rica é a instrução ao sósia (Clot, 1999), ou a autoconfrontação simples e cruzada (Clot, 1999, 2008; Clot, Faïta, Fernandez \& Scheller, 2000). São técnicas que utilizam outras formas de mediação semiótica que não a linguagem falada (em sentido estrito), como, por exemplo, fotos e filmagens. Embora se possa antever problemas logísticos e operacionais em seu uso, ainda mais quando consideramos os contextos de realização do trabalho sujo, estas duas técnicas propõem a recuperação de outras dimensões da atividade de trabalho, tais como as ferramentas de mediação utilizadas, sua inserção nos coletivos e num gênero profissional (ou seja, na atividade de outros), e os aspectos ambientais/contextuais mais amplos.

Uma segunda sugestão, desdobramento lógico dos argumentos aqui desenvolvidos, é de que o estudo do trabalho sujo não se esgota nas atividades "externas" aos contextos organizacionais em sentido estrito, caracterizadas pelo emprego informal, precário, marginalizado, excluído. Como discutido no artigo, estes são, de fato, contextos de investigação dos psicólogos sociais do trabalho em nosso país, em seu esforço de ampliação e diversificação da agenda de pesquisas e compromisso social. Porém, o trabalho sujo também ocorre no "interior" das organizações "tradicionais". 
A consideração desse espectro mais amplo, por meio do conceito de trabalho sujo, pode permitir aos pesquisadores problematizarem a dinâmica do sistema social de modo mais holístico, capturando processos e dinâmicas que atravessam o trabalho na atualidade em seus diversos contextos e formas de institucionalização. Será possível discutir, por exemplo, os vários usos de "sujo" pelas organizações na atualidade, e seus mecanismos de funcionamento e consequencias. É exatamente nessa direção que Dejours (1999) discute "trabalho sujo", como sendo um trabalho a serviço da banalização do mal, das injustiças, do sofrimento (como o trabalho sujo observado no holocausto, por exemplo). Neste ponto, antevemos um promissor diálogo no interior da psicologia social do trabalho, quando, por meio da discussão do trabalho sujo, nos aproximamos da crítica social.

\section{Referências}

Arantes, P. (2011). Sale boulot: uma janela sobre o mais colossal trabalho sujo da história. Tempo Social, 53(1), 31-66.

Ashforth, B. E., \& Kreiner, G. E. (1999). "How can you do it?": Dirty work and the challenge of constructing a positive identity. Academy of Management Review, 24(3), 413-434.

Barros, V. A. (2010). O trabalho do profissional psicólogo: construindo uma posição crítica. In Conselho Federal de Psicologia (Ed.), Psicologia crítica do trabalho na sociedade contemporânea (pp. 57-64). Brasília: Conselho Federal de Psicologia.

Barros, V. A., \& Lhuilier, D. (2013). Marginalidade e reintegração social. In L. de O. Borges \& L. Mourão (Orgs.), O Trabalho e as organizações (pp. 669-694). Porto Alegre: Artmed.

Barros, V. A., \& Santos, P. H. F. (2013). Lactivité marginale. Nouvelle Revue de Psychosociologie, 16, 93-110.

Bendassolli, P. F. (2011). Crítica às apropriações psicológicas do trabalho. Psicologia $\mathbb{E}$ Sociedade, 23(1), 75-84.

Bendassolli, P. F. \& Soboll, L. A. (2011). Clínicas do trabalho. São Paulo: Atlas.

Bendassolli, P. F., Borges-Andrade, J. E., \& Malvezzi, S. (2010). Paradigmas, eixos temáticos e tensões na PTO no Brasil. Estudos de Psicologia, 15(3), 281-289.

Bolton, S. C. (2007). Dimensions of dignity at work. London: Butterworth Heineman.

Canguillhem, G. (1984). Le normal et le pathologique. Paris: PUF.

Castel, R. (1999). As metamorfoses da questão social (I. D. Poleti, Trad.). Petrópolis: Vozes. (Original publicado em 1995)

Clot, Y. (1995). Le travail sans l'homme? Paris: La Découverte.

Clot, Y. (1999). La fonction psychologique du travail. Paris: PUF.

Clot, Y. (2002). Clinique de l'activité et répétition. Cliniques Méditerranéennes, 66, 31-53.

Clot, Y. (2008). Travail et pouvoir d'agir. Paris: PUF.

Clot, Y. (2010). Le travail à coeur. Paris : La Découverte.

Clot, Y., Faïta, D., Fernandez, G., \& Scheller, L. (2000). Entretiens en autoconfrontation croisée: une méthode en clinique de l'activité. Pistes, 2(1), 1-7.

Clot, Y., \& Lhuilier, D. (2010). Travail et santé. Paris : Érès.

Da Rocha Falcão, J. T. (2008). Os saberes oriundos da escola e aqueles oriundos da cultura extraescolar: hierarquia ou complementaridade? Saber $\mathcal{E}$ Educar, 13, 109-123.

Da Rocha Falcão, J. T. (2012, abril). O trabalho sujo como arena da desmedida. Comunicação oral apresentada no I Colóquio Internacional de Psicossociologia do Trabalho, Belo Horizonte, Minas Gerais, Brasil.

Dejours, C. (1999). A banalização da injustiça social. Rio de Janeiro: FGV.

Dias, S. M. (2006). Coleta seletiva e inserção cidadã. In P. Jacobi (Org.), Gestão compartilhada dos resíduos sólidos: inovação com inclusão social (pp. 65-87). São Paulo: Annablume.

Drew, S. K., Mills, M., \& Gassaway, B. M. (2007). Dirty work. Wako, TX: Baylor University Press.

Grima, F., \& Muller, R. (2006). Faire face à la violence au travail. Gérer et Comprendre, 85, 37-48.

Hughes, E. (1951). Work and the Self. In J. H. Rohrer \& M. Sherif (Eds.), Social psychology at the crossroads (pp. 313-323). New York: Harper.

Hughes, E. C. (1958). Man and their work. Glencoe, IL: Free Press.

Hughes, E. (1962). Good people and dirty work. Social Problems, 10(1), 3-11. 
Koppe, S. (2012). A moderate eclecticism: Ontological and epistemological issues. Integrative Psychological and Behavioral Science, 46(1), 1-19.

Leite, T. J. C., Oliveira, A. A., \& Pinto de Paula, P. (2012, abril). A saúde e cidadania dos agentes da limpeza urbana de Belo Horizonte sob a perspectiva da psicodinâmica do trabalho. Comunicação oral apresentada no I Colóquio Internacional de Psicossociologia do Trabalho, Belo Horizonte, Minas Gerais, Brasil.

Leontiev, A. N. (1978). Activity, consciousness, and personality. Englewood Cliffs: Prentice-Hall.

Lhuilier, D. (2002). Placardisés. Des exclus dans l'entreprise. Paris : Seuil.

Lhuilier, D. (2005). Le sale boulot. Travailler, 2(14), 73-98. Lhuilier, D. (2006). Cliniques du travail. Paris : Érès.

Mansur, F. (2012). As ocupações precárias e o desemprego disfarçado. Revista do Instituo Humanitas Unisinos on-line, 12(390). Recuperado de http://www. ihuonline.unisinos.br/index.php?option $=$ com_con tent\&view $=$ article\&id $=4387 \&$ secao $=390$

Ministério do Trabalho e Emprego. (2010). Classificação brasileira de ocupações. Brasília: Autor. Recuperado em http://www.mtecbo.gov.br/cbosite/pages/ downloads.jsf

Sato, L. (2010). Psicologia, saúde e trabalho: distintas construções dos objetos "trabalho" e "organizações". In Conselho Federal de Psicologia (Ed.), Psicologia crítica do trabalho na sociedade contemporânea (pp. 47-53). Brasília: Conselho Federal de Psicologia.
Spink, P. K. (1996). A organização como fenômeno psicossocial: notas para uma redefinição da psicologia do trabalho. Psicologia EO Sociedade, 8(1), 174-192.

Taques, A. (Diretor), \& Leal, D. (Produtor). (2012). Passa o rodo. Natal: Pau-a-Pixel.

Santiago-Delefosse, M. (2004). Activité et émotions: une perspective développementale des émotions comme instruments psychologiques. Bulletin de Psychologie, 57(1), 29-36.

Schwartz, Y. (1994). Travail et philosophie: convocations mutuelles. Toulouse: Octarès.

Sévérac, P. (2009). Conhecimento e afetividade em Spinoza. In A. Martins (Org.), O mais potente dos afetos: Spinoza e Nietzsche (pp. 17-58). São Paulo: Martins Fontes.

Silva, A. K., Da Rocha Falcão, J. T., Torres, C. C., \& Moreira, J. (2012). O trabalho encarcerado como contexto específico de reprodução de condições gerais do mundo do trabalho. In R. Figueiró (Org.), Saúde e Sistema prisional: impasses e possibilidades do RN. Natal: Editora UnP.

Simpson, R., Slutskaya, N., Lewis, P., \& Höpfl, H. (2012). Dirty Work: Concepts and identities. Londres: Palgrave.

Spinoza, B. (1965). Éthique. Paris: Flammarion. (Original publicado em 1677)

Viana, H. V., Maia Filho, O. N., Oliveira, J. C., da., \& Pereira Neto, F. E. (2012). Contribuições de Baruch Espinosa à teoria histórico-cultural. Psicologia em Revista, 18(1), 134-147. 